\title{
Publisher's Note: Multiscale dynamics of helicity-dependent all-optical magnetization reversal in ferromagnetic Co/Pt multilayers [Phys. Rev. B 96, 224421 (2017)]
}

R. Medapalli, D. Afanasiev, D. K. Kim, Y. Quessab, S. Manna, S. A. Montoya,

A. Kirilyuk, Th. Rasing, A. V. Kimel, and E. E. Fullerton

(Received 20 December 2017; published 29 December 2017)

DOI: 10.1103/PhysRevB.96.219902

This paper was published online on 15 December 2017 with errors in the presentation of Figs. 3 and 4 . The figures have been replaced as of 20 December 2017. The figures are correct in the printed version of the journal. 